\title{
Reseña. Enseñar y aprender lenguas en un modelo educativo plurilingïe: Metodologías y estrategias para el desarrollo de proyectos educativos y para la práctica docente, coordinado por Mònica Pereña, 2018
}

\author{
Horsori Editorial, 234 pp., 23,00 €, ISBN: 978-84-947780-7-0 \\ Maria Teresa Sans Bertran \\ Universitat Autònoma de Barcelona
}

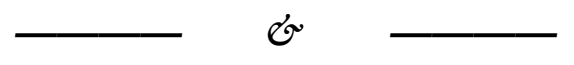

Pereña señala, en un libro compuesto por siete capítulos de diferentes autores especialistas en el ámbito de la educación plurilingüe, que uno de los retos educativos de la sociedad del siglo XXI es dar respuesta a las necesidades lingüísticas plurilingües a partir de 1) nuevos modelos educativos inclusivos e interculturales y 2) recursos y herramientas para afrontarlos. La evolución demográfica de las sociedades y las migraciones son factores que aportan diversidad cultural y lingüística a las poblaciones, que cada vez son más heterogéneas. Así mismo, el tratamiento de la diversidad lingüística en las aulas debe ser respaldado por todos los docentes, sea cual sea su especialidad, con el fin de desarrollar la competencia comunicativa y los repertorios lingüísticos e interculturales de los alumnos. A lo largo del libro, se hace un repaso de metodologías, proyectos y actuaciones docentes que permiten enseñar y aprender lenguas en un modelo educativo plurilingüe.

El capítulo 1, El aprendizaje integrado de las lenguas, se estructura en tres partes. En la primera parte, titulada Estrategias de transferencia interlingüística en el aprendizaje de lenguas adicionales: un Enfoque Plurilingüe Integrador (EPI), las autoras Esteve y González introducen conceptos relacionados con la enseñanza y el aprendizaje de las lenguas como son el multilingüismo, el plurilingüismo, la competencia plurilingüe e intercultural y el translanguaging. A partir de las diferencias de significado de los conceptos y sus interrelaciones, las autoras proponen adoptar un Enfoque Plurilingüe Integrador (EPI) como planteamiento didáctico para el logro efectivo de la competencia plurilingüe e intercultural de los alumnos en el aula de lengua adicional. El enfoque se basa en un uso reflexivo de la lengua que permite 
a los alumnos interiorizar nuevos conceptos y saber usarlos en situaciones comunicativas reales de interacción lingüística y cultural dejando de lado las reflexiones metalingüísticas como un fin en sí mismas. Además, el capítulo pone especial énfasis en la idea que el Enfoque Plurilingüe Integrador puede adoptar distintas metodologías las cuales permiten la activación de estrategias de transferencia interlingǘstica como la intercomprensión, desarrollada por Clua en la segunda parte del capítulo titulada "La intercomprensión". Dicha estrategia se basa en el reconocimiento de elementos nuevos y correspondencias entre la lengua del alumno y las lenguas que son objeto de aprendizaje. A partir de aquí, las autoras proponen prácticas pedagógicas que pueden integrar el EPI como por ejemplo el Trabajo en Secuencias Didácticas (TSD), el Pedagogically Based Code-Switching (PBCS) o el Translation for Other Learning Contexts (TOLC).

Posteriormente, Fidalgo y Mayans en "La gestión de la diversidad lingüística y la escuela catalana" (tercera parte del capítulo) describen la diversidad lingüística presente en las aulas de Cataluña dibujando un mapa de las zonas geográficas de los alumnos y las lenguas que hablan. Las zonas geográficas de donde provienen son el Magreb (34,2\%), América del Sur y Central (26,9\%), la Unión Europea $(14,7 \%)$, Asia y Oceanía (12,6\%), África no magrebí (6,6\%), Europa no comunitaria $(4,7 \%)$ y América del Norte $(0,4 \%)^{1}$ y se estima que en las aulas se hablan más de 106 lenguas. Es evidente la incorporación de alumnos procedentes de otros países en los centros escolares pero ¿cómo se gestiona la diversidad lingüística en las aulas? Los autores indican aportaciones relevantes del Departament d'Educació para atender esta realidad: la incorporación y la presencia de la lengua familiar en la práctica educativa que permita al alumno construir una nueva identidad compartida que no implique la renuncia a sus repertorios lingüísticos y culturales. A partir de estas nuevas líneas de actuación se diseñan el programa de inmersión lingüística del catalán, los currículums escolares de Cataluña y algunos materiales didácticos como el dosier Waramurungundi. La sostenibilitat $i$ la diversitat lingüística a l'aula y Jocs LIC. Además, se diseñan estrategias y políticas para la integración socioeducativa de los alumnos estableciendo convenios con entidades vinculadas a los países de origen cuyo compromiso es ofrecer, a todo el alumnado interesado, clases de las lenguas y de las culturas de origen del alumnado de nacionalidad extranjera dentro y fuera del horario escolar. También hay centros que ofrecen clases de lengua y cultura catalanas a las familias con el objetivo de compartir experiencias e implicar a las familias en el proceso de integración.

\footnotetext{
${ }^{1}$ Datos del Departament d'Educació (Generalitat de Catalunya), 2015.
} 
El capítulo 2, titulado El aprendizaje de las lenguas desde los contenidos, también se estructura en tres partes. En la primera, Pascual sienta las bases para comprender qué es el Tratamiento Integrado de las Lenguas y Contenidos (TILC). Más concretamente, se centra en abordar los principios del enfoque TILC, los objetivos y las aportaciones del enfoque en relación a la mejora de los alumnos en todas las materias y para afrontar la diversidad dentro de un modelo educativo plurilingüe. Finalmente, Pascual destaca en esta parte del capítulo la flexibilidad del enfoque para adaptarse a los diferentes contextos de diversidad del aula, ya sea por diversidad lingüística, por diferencia en los grados de competencia en la lengua vehicular y de los conocimientos disciplinarios. Además, el autor indica que el TILC permite atender la diversidad a partir de recursos como la construcción dialógica de conocimientos, el aprendizaje cooperativo y/o el andamiaje a todos los niveles.

A continuación, las autoras Canal y Marco, en la segunda parte del capítulo titulada La inmersión lingüistica en el sistema educativo de Cataluña o cómo aprender una lengua a la vez que se aprenden contenidos, realizan una revisión histórica de la renovación pedagógica en Cataluña en los años 80 poniendo énfasis en el modelo educativo de la época basado en la implementación de programas de inmersión lingüística en lengua catalana en un contexto donde el alumnado era mayormente monolingüe en castellano y cuyo objetivo era asegurar la adquisición de competencias lingüísticas en catalán y castellano del alumnado así como la igualdad de oportunidades. Eso sí, las autoras destacan la comprensión de ese programa de los años 80 para entender que un nuevo modelo de inmersión lingüística es necesario para dar respuesta a las necesidades de la Cataluña del siglo XXI, donde hay más alumnado extranjero, más movilidad en las aulas y donde el número de lenguas que se hablan dentro de una aula es muy superior. Finalmente, las autoras describen aspectos relevantes que deben tener en cuenta los docentes para aplicar de forma adecuada el programa de inmersión lingüística. Algunos aspectos a tener en consideración son: la metodología, las características personales que inciden en el aprendizaje de una L2, la vinculación de las familias y de sus repertorios lingüísticos dentro del programa y el mantenimiento de unos usos lingǘsticos coherentes en diferentes situaciones escolares.

En la tercera parte Alumnos competentes a través de proyectos que integren contenidos y lengua extranjera de este mismo capítulo, Felip y Lobo dedican su atención a las actuaciones AICLE (Aprendizaje Integrado de Contenidos y Lengua Extranjera) y señalan las necesidades de los centros y de los docentes para implementarlas. Entre ellas destacan que los docentes deben dominar los contenidos de aprendizaje, un nivel C1 mínimo de la lengua en la que se impartirán los 
contenidos, una buena formación metodológica y un dominio de la tecnología que ayude al profesor a dar las clases con actuaciones AICLE. Finalmente, el apartado aporta casos prácticos de proyectos AICLE que se han implementado con éxito.

En el capítulo 3, La acogida lingüística del alumnado de procedencia extranjera, Mayans y Sánchez presentan, de forma clara y detallada, los aspectos lingüísticos en los que se centran las políticas de atención al alumnado de procedencia extranjera en los centros de Cataluña. Después de una breve descripción sobre el contexto escolar en Cataluña, los autores indican tres prioridades educativas para los alumnos recién llegados: (1) el éxito educativo; (2) las necesidades de tener relaciones afectivas hacia las nuevas lenguas y hacia la educación intercultural y (3) la relevancia de que adquieran en la escuela competencia conversacional y lenguaje académico. A partir de aquí, los autores profundizan en el proceso de acogida de los alumnos recién llegados y de origen extranjero desde un entorno educador y una perspectiva inclusiva. Mediante un esquema (p. 132), Mayans y Sánchez presentan el itinerario escolar de los alumnos, quienes reciben una acogida inicial, continúan con el aula de acogida para adquirir un aprendizaje inicial y comunicativo de la lengua y, finalmente, pasan al aula ordinaria donde se les facilita el acceso al lenguaje académico que vehicula los contenidos curriculares. Seguidamente, el capítulo incluye diversos gráficos que muestran, entre otros, datos cuantitativos sobre el número de aulas de acogida, el número de alumnos por países, el tipo de escolarización previa del alumnado de las aulas de acogida y el porcentaje de alumnos que después de la acogida superan el examen A2 del Marco común europeo de referencia para las lenguas: aprender enseñar y evaluar (MCER). Los datos discutidos a lo largo del capítulo ponen de manifiesto que la acogida inicial de los alumnos se ha realizado de forma satisfactoria. Sin embargo, los autores indican que el reto actual está en las aulas ordinarias y proponen el Tratamiento Integrado de las Lengua y Contenidos como una metodología que permite a los centros avanzar hacia la escuela inclusiva.

El capítulo 4 ¿De la evaluación al aprendizaje o a la inversa? de Figueras es especialmente relevante debido a que uno de los retos de los docentes es entender y utilizar la evaluación en las aulas. Evaluar implica conocer el progreso de los alumnos, emitir valoraciones y/o calificaciones. En este capítulo, la autora tiene como objetivo principal hacer reflexionar a los docentes acerca de la evaluación y generar ideas para que los docentes seleccionen con criterio actuaciones evaluativas. Se presenta un breve estado de la cuestión sobre la evaluación como disciplina donde se describe el concepto evaluación y se presentan trabajos teóricos recientes. Seguidamente, la autora señala las dificultades de los docentes para evaluar y, 
finalmente se introducen algunas propuestas de evaluación. Aunque todos los contenidos del capítulo son de interés, destacamos la dicotomía que existe entre la necesidad de un nuevo modelo de enseñanza donde el alumno aprende de una manera más participativa y las presiones establecidas por conseguir unos buenos resultados que reflejen los logros de los alumnos. La autora indica la complejidad de combinar enfoques metodológicos activos, que usan estrategias de evaluación formativa, con pruebas externas, que tienen un diseño y unas estructuras para evaluar muy diferentes. Para intentar dar respuesta a este reto, la autora propone acercarnos a los cinco principios básicos de la evaluación formativa: compartir y comprender los objetivos de aprendizaje, llevar a cabo actividades en el aula que permitan evidenciar aprendizajes, dar feedback que permita avanzar en los aprendizajes, activar a los alumnos como recursos de aprendizaje entre ellos y, finalmente, hacer a los alumnos sujetos de sus aprendizajes.

En el capítulo 5, Boyd y Lorenzo presentan Los aprendizajes integrados en los proyectos escolares: el enriquecimiento competencial con ABP (Aprendizaje Basado en Proyectos). Las autoras hacen, a lo largo del capítulo, una revisión valorativa de las secuencias en el aprendizaje por proyectos y la complementan con ejemplos prácticos. Son relevantes las aportaciones de las autoras, que ponen en valor el aprendizaje basado en proyectos como una estrategia fundamental para un modelo de escuela competencial y como una alternativa que engloba metodologías activas que ponen énfasis, sobre todo, en la competencia de aprender a aprender, aprender a ser y aprender a estar. Finalmente añaden que el modelo se orienta a la adquisición de competencias comunicativas que permiten a los alumnos interaccionar con los demás y abrirse al entorno cultural.

Seguidamente, Serra, en el capítulo 6, titulado Plurilingüismo y aprendizaje no formal e informal, resalta la idea que la competencia plurilingüe evoluciona y se desarrolla a lo largo de la vida a través de la educación formal y de la educación no formal e informal. Así mismo, el autor señala condiciones que favorecen el aprendizaje alternativo de lenguas como, por ejemplo, el aumento de la exposición a las lenguas, sobre todo en el medio digital.

El libro termina con el capítulo 7, titulado El nuevo rol del profesorado: nuevas competencias para nuevos aprendizajes. Pereña, a modo de conclusión, plantea que la transformación de las sociedades y la diversidad lingüística y cultural han propiciado la aparición de los retos educativos que se describen a lo largo del libro. Sin embargo, esta autora indica un elemento clave para dar respuesta a esos retos: la transformación del rol del profesorado, entendiéndolo como un agente 
activo del cambio educativo. Finalmente, propone hacer a los profesores partícipes de un proyecto con un liderazgo pedagógico compartido que les permita trabajar en equipo con toda la comunidad educativa para llevar a las aulas las nuevas prácticas pedagógicas y educativas señaladas a lo largo de los capítulos que componen el libro.

\section{REFERENCIAS}

Pereña, M. (Coord.) (2018). Enseñar y aprender lenguas en un modelo educativo plurilingüe. Metodologías y estrategias para el desarrollo de proyectos educativos y para la práctica docente. Barcelona: Horsori Editorial.

\section{MARIA TERESA SANS BERTRAN}

Graduada en Educación Primaria y Máster en Investigación en Didáctica de la Lengua y la Literatura por la Universitat Autònoma de Barcelona. Actualmente, es maestra en una escuela de adultos y realiza su tesis doctoral sobre las creencias y las estrategias docentes para la enseñanza de la lengua oral en una escuela de adultos de un centro penitenciario de Cataluña bajo la dirección de la Dra. Marilisa Birello (Universitat Autònoma de Barcelona).

mariateresa.sans@uab.cat

Sans Bertran, M. T. (2020). Reseña. Enseñar y aprender lenguas en un modelo educativo plurilingüe: Metodologías y estrategias para el desarrollo de proyectos educativos y para la práctica docente, coordinado por Mònica Pereña, 2018. Bellaterra Journal of Teaching \& Learning Language \& Literature, 13(1), 77-82. https://doi.org/10.5565/rev/jtl3.804 